Review

\title{
Mechanistic aspects of vanadium catalysed oxidations with peroxides
}

\author{
Valeria Conte ${ }^{\mathrm{a}, *}$, Alessia Coletti $^{\mathrm{a}}$, Barbara Floris $^{\mathrm{a}}$, Giulia Licini $^{\mathrm{b}}$, Cristiano Zonta $^{\mathrm{b}}$ \\ a Dipartimento di Scienze e Tecnologie Chimiche, Università di Roma “Tor Vergata”, Via della Ricerca Scientifica snc, 00133 Roma, Italy \\ b Dipartimento di Scienze Chimiche, Università di Padova, Via Marzolo 1, 35131 Padova, Italy
}

\section{Contents}

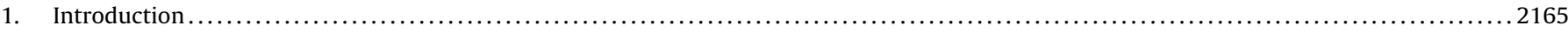

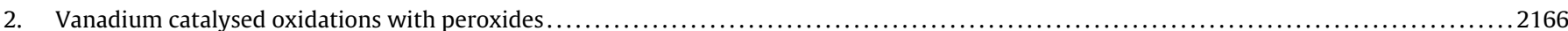

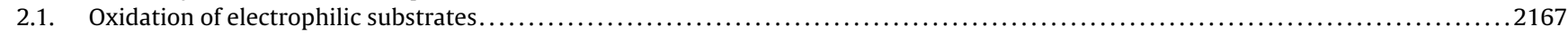

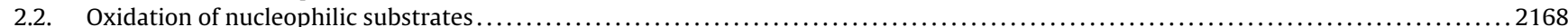

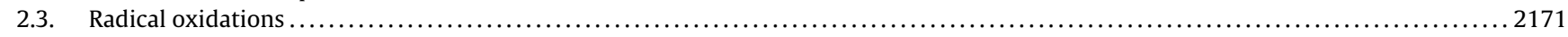

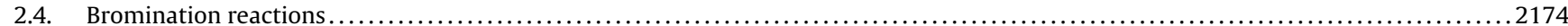

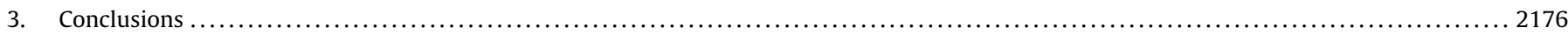

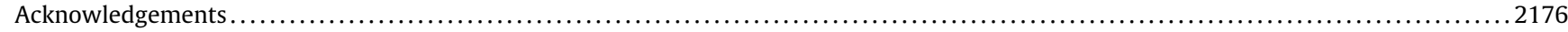

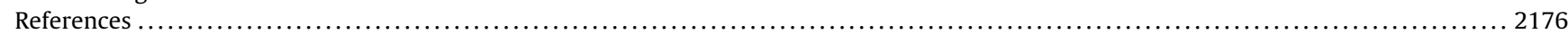

\section{A R T I C L E I N F O}

\section{Article history:}

Received 30 December 2010

Accepted 6 March 2011

Available online 16 March 2011

\section{Keywords:}

Oxidations

Vanadium

Peroxides

Reaction mechanisms

Bromination

\begin{abstract}
A B S T R A C T
The enhancement of the reactivity of peroxides, particularly hydrogen peroxide and alkylhydroperoxides, in the presence of vanadium catalysis is a very well known process. The catalytic effect is determined by the formation of an intermediate whose nature depends on the peroxides used and on its interaction with the metal precursor, high-valent peroxo vanadium species being usually the reactive oxidants. During the last decades the mechanistic details for several types of oxidation reactions have been elucidated. Interestingly, in a number of cases theoretical calculations offered support to the proposed reaction pathways.

In general, $\mathrm{V}(\mathrm{V})$ peroxo species behave as electrophilic oxygen transfer reagents thus reacting preferentially with the more nucleophilic functional group present in the molecule. In several instances the chemoselectivity observed in such processes is very high when not absolute. As far as vanadium peroxides are concerned, a radical oxidative reactivity toward alkanes and aromatics has been also observed; also for this latter chemistry, diverse research groups studied in detail the mechanism. On the other hand, no clear-cut evidence of nucleophilic reactivity of vanadium peroxo complexes has been obtained.

Here we collect a selection of recent achievements concerning the reaction mechanisms in the vanadium catalysed oxidation and bromination reactions with peroxides.
\end{abstract}

(C) 2011 Elsevier B.V. All rights reserved.

\section{Introduction}

Vanadium is present in the sea water, in fresh water and in soils both as vanadate, $\mathrm{V}(\mathrm{V})$, and vanadyl, $\mathrm{O}=\mathrm{V}(\mathrm{IV})[1]$; thus it is well accessible for living organisms, particularly in marine environment. Even though this metal has been known since 1831, the several roles of vanadium in enzymatic and medicinal chemistry have only been clearly demonstrated since the 1980s [2,3]: i.e. involvement in the activity of V-dependent haloperoxidases (VHalPO) [4] and nitrogenases $[3,5]$ enzymes, as well as insulin-enhancing effect in the treatment of human diabetes of type 2 [6]. Vanadate dependent

\footnotetext{
* Corresponding author. Tel.: +39 0672594014; fax: +390672594328

E-mail address: valeria.conte@uniroma2.it (V.Conte).
}

bromoperoxidases, $\mathrm{VBrPO}$, isolated from red and brown algae, are the most known and studied examples of V-dependent enzymes [4]. Their task is to efficiently catalyse the oxidation of bromide ions by hydrogen peroxide, accordingly playing a major role in the biosynthesis of brominated natural compounds. The catalytic cycle of VBrPO involves, as fundamental step, the formation in the active site of a peroxovanadium species, which is a much stronger oxidant than $\mathrm{H}_{2} \mathrm{O}_{2}$. The peroxo derivative oxidizes the bromide ion to a brominating intermediate which then reacts either with the substrate or with another $\mathrm{Br}^{-}$to form bromine. An accepted mechanistic proposal for such enzymatic process can be outlined as in Scheme 1.

More connected with bench and fine chemistry is the reactivity of vanadium peroxides toward several different organic and inorganic substrates like thioethers, alkenes, alcohols, aromatic and 


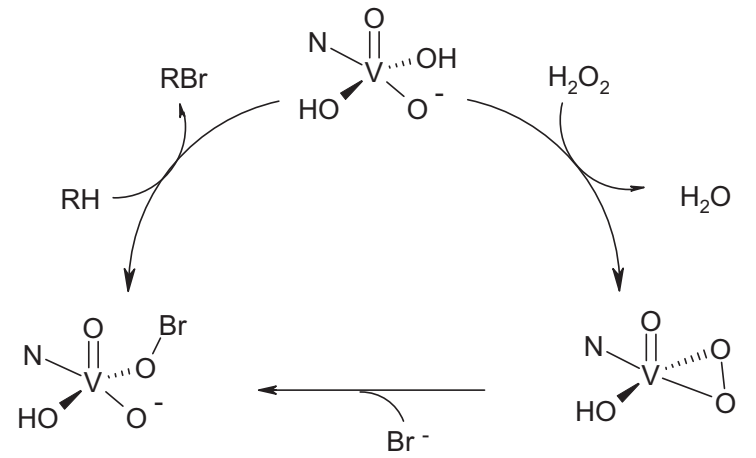

Scheme 1. Bromide ion oxidation mechanism in the active site of a vanadium dependent bromoperoxidase enzyme [7].

aliphatic hydrocarbons, halides and sulfur dioxide, as summarized in Scheme $2[8,9]$.

These reactions, either stoichiometric or catalytic with the use of hydrogen peroxide or an alkylhydroperoxide as terminal oxidant, are generally carried out in mild conditions and are characterized by very high yields and selectivity. The enantioselective version of some of these processes has also been reported $[8,9]$.

Upon addition of $\mathrm{H}_{2} \mathrm{O}_{2}$ to vanadium precursors several peroxo vanadates can form in solution depending on $\mathrm{pH}$, the presence of additional ligands and relative concentrations of the reagents. In recent times, we proposed, as a multipurpose tool, the association of ESI-MS (electrospray ionization mass spectrometry) with ${ }^{51} \mathrm{~V}$ NMR spectroscopy and theoretical calculations to achieve a detailed speciation of the $\mathrm{V}(\mathrm{V})-\mathrm{H}_{2} \mathrm{O}_{2}-\mathrm{H}^{+}$-ligand systems [10-12]. With such a protocol, the identification of vanadium peroxo complexes has been obtained, in several experimental conditions, and this greatly helped in understanding the mechanisms and products distribution of reactions where such species are involved.

Our work carried out to characterize vanadates and peroxovanadates solutions is already summarised in rather recent reviews [11-13] and interested readers are thus referred there or to the original papers $[10,14-16]$ in order to find more details. Nevertheless, some of the main conclusions in the field will be considered here, when necessary to help in the discussion.
In this, by no means exhaustive, review dedicated to studies concerning the mechanistic features of vanadium catalysis in oxidations with peroxides, we mainly concentrate on the peculiar performance of various V-peroxo derivatives toward alkenes, alkynes and aromatics. In addition to the classical epoxidation or hydroxylation reactions, we also call attention to oxybromination of double and triple bond.

$\mathrm{V}(\mathrm{V})$ peroxo species act in the majority of instances as electrophilic oxygen transfer reagents, thus reacting preferentially with the more nucleophilic functional group present in the molecule: the chemoselectivity observed in such processes is usually very high when not absolute $[8,9,22]$. A radical oxidative reactivity toward alkanes and aromatics has been also observed with vanadium peroxides, particularly when certain ligands (i.e. picolinate anion) are bound to the metal centre. Diverse research groups studied in detail such quite complicate mechanisms $[8,9,22]$. On the other hand, no direct evidence of nucleophilic oxidative activity of vanadium peroxo complexes have been obtained.

Besides, we shall also discuss our interesting and more recent results achieved using ionic liquids (ILs) as solvents in place of the classical chlorinated molecular ones [17]. This aspect attracted our interest, in order to apply in our systems one of the stringent modern requirements of "Green Chemistry" [18], i.e. the reduction of the amount of volatile organic compounds (VOCs) in synthetic innovative procedures.

\section{Vanadium catalysed oxidations with peroxides}

The catalytic species derived from interaction of hydrogen peroxide or alkyl hydroperoxides with suitable transition metal ions, are considered among the most active oxidants $[8,9,19,20]$ toward several organic and inorganic substrates. Understanding of the mechanism of these processes is evidently crucial not only to predict the nature of the products in a given process but also the stereochemical outcome in asymmetric reactions.

Numerous indications have been obtained in the years that, depending on the nature of the substrate, of the oxidant and also of the coordination sphere of the catalysts, different types of mechanisms may operate. Recent book chapters [9,19-21] and reviews $[8,22,23]$ have been dedicated to this topic. Furthermore, this general behaviour applies also to vanadium catalysis [21,24]. As a

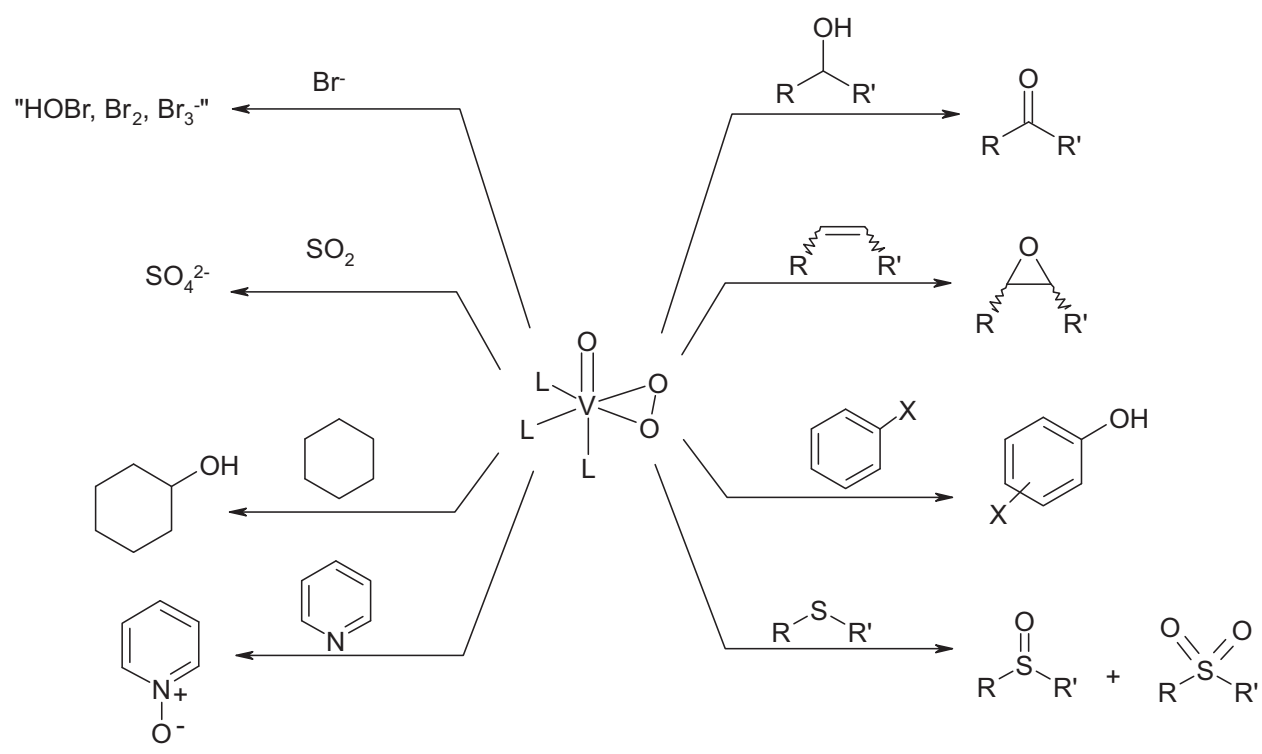

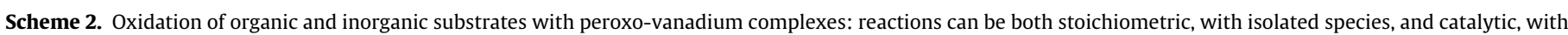
$\mathrm{H}_{2} \mathrm{O}_{2}$ as terminal oxidant $[8,9]$. 


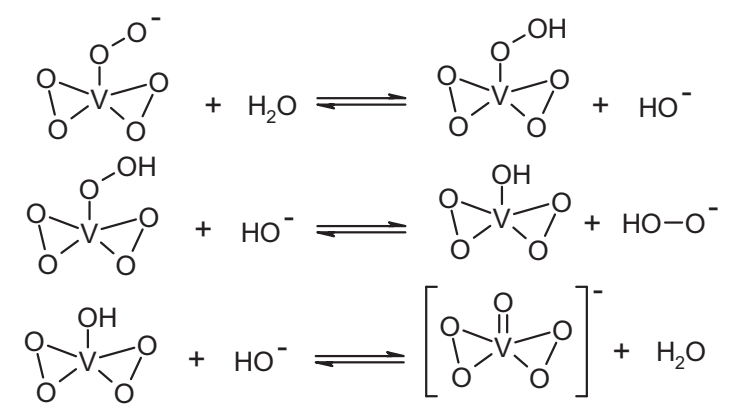

Scheme 3. Hydrolysis of triperoxo vanadates in alkaline solutions [31].

matter of fact, some of the initial mechanistic studies in epoxidation reactions have been performed with $\mathrm{V}(\mathrm{V})$ precursors $[21,22]$.

\subsection{Oxidation of electrophilic substrates}

Peroxo metal complexes are known as nucleophilic oxidants with sufficiently electrophilic substrates [25]. The accepted mode of action is a bimolecular 1,3-dipolar addition of the $\mathrm{M}^{+}-\mathrm{O}-\mathrm{O}^{-}$species to electrophilic dipolarophiles, such as electron poor olefins $[25,26]$ (see Eq. (1)), forming a peroxymetallacycle intermediate.

$$
\mathrm{L}_{\mathrm{n}} \mathrm{M}_{-\mathrm{O}}^{-\mathrm{O}}+\mathrm{J}^{\mathrm{EWG}} \longrightarrow
$$

This type of reactivity is typical for Pt derivatives, in particular with kinetic studies on hydroxo species it has been shown that the metal plays two different roles: it activates hydrogen peroxide increasing its nucleophilicity and the substrate toward the nucleophilic attack by coordination to the metal centre. As a further example of nucleophilic reactivity, the same Pt catalyst is also active in Baeyer-Villiger oxidation of ketones.

Analogous reactivity has been observed with bisperoxo methyltrioxorhenium complex which acts as a nucleophilic oxidant in Baeyer-Villiger reactions [27]. Evidence of the nucleophilicity of the peroxo rhenium species has been obtained via Adam probe oxidation [28].

Returning to vanadium, reports claimed $[29,30]$ that triperoxo derivatives behave as nucleophilic oxidants. In particular, the efficient oxidation of $\alpha, \beta$-unsaturated ketones to the corresponding epoxide, and of diphenylethanedione to benzoic acid, reactions usually carried out with alkaline $\mathrm{H}_{2} \mathrm{O}_{2}$, was obtained with complexes $\mathrm{A}\left[\mathrm{V}\left(\mathrm{O}_{2}\right)_{3}\right] \cdot 3 \mathrm{H}_{2} \mathrm{O}(\mathrm{A}=\mathrm{Na}$ or $\mathrm{K})[29,30]$.

With the aim to clarify this controversial aspect of the chemistry of peroxo vanadates, we studied in depth the oxidation of cyclobutanone to 4-hydroxybutanoic acid with the blue-violet complex $\mathrm{Na}\left[\mathrm{V}\left(\mathrm{O}_{2}\right)_{3}\right] \cdot 3 \mathrm{H}_{2} \mathrm{O}$, in alkaline alcohol/water mixtures [31]. The complex is not stable in aqueous solution and a fast change of colour from blue-violet (triperoxo vanadate) to yellow (diperoxo vanadate) is observed. The yellow solution thus obtained has a $\mathrm{pH}$ of about 11 due to the hydrolysis of the triperoxo derivative (see Scheme 3 ). In such basic conditions, the peroxy anion can evolve from triperoxo vanadates furnishing the hydroperoxy anion which is well known for its effectiveness as nucleophile in Baeyer-Villiger type oxidations.

Indeed, the kinetic behaviour observed in the oxidation with $\mathrm{H}_{2} \mathrm{O}_{2}$ of cyclobutanone in basic conditions ( $\mathrm{pH} 11$ ) both in the presence and in the absence of $\left.\left[\mathrm{V} \mathrm{O}_{2}\right)_{3}\right]^{-}$is very similar. This has been taken as a clear evidence that in highly alkaline solutions the hydroperoxy anion forms and it is the bona fide oxidant. In agree-

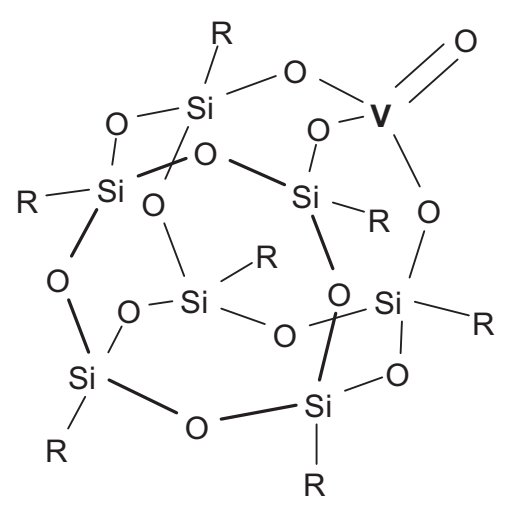

Fig. 1. $V(V)$ silsesquioxane trisilanolate (VPOSS) [32].

ment with this hypothesis, when the vanadium triperoxo vanadate complex is present, the reaction proceeds only through the slow release of the $\mathrm{HOO}^{-}$anion. Therefore, the claims on nucleophilic reactivity of triperoxo vanadates are undoubtedly incorrect.

Other interesting reports appeared more recently, dealing with the catalytic activity of silsesquioxane trisilanolate $V(V)$ complex (see Fig. 1 ) in sulfoxidations and $\mathrm{N}$-oxidation reaction with cumyl hydroperoxides (CHP) [32]. Detailed kinetic studies reveal [32] that $\mathrm{V}(\mathrm{V})$ silsesquioxane trisilanolate (V-POSS) exhibits a high catalytic activity which, in the presence of an additional ligand, can be further increased.

To shed more light onto this effect, the sulfoxidation reaction in the presence of different coligands (compounds a-f, Fig. 2) of increasing basic strength was carried out.

The addition of such species to the reaction mixtures resulted in increased reactivity and in a variation of the sulfone/sulfoxide ratio; the effects correlate with the electron richness of the coligand the most electron-rich being the most effective.

The catalytic activity of V-POSS has been also examined in the oxidation of triethylamine to the corresponding $N$-oxide: the reaction showed a sigmoid kinetic profile suggesting that the initially formed $\mathrm{N}$-oxide coordinates to the metal centre, increasing the catalytic activity of the system. Further support for this behaviour was obtained by initial addition of 5 equiv. of $\mathbf{f}$ (see Fig. 2) to the reaction mixture and observing an increase of the rate with no change in the yields.

In the oxidation of dibenzylamine to the corresponding nitrone, a process known to occur via the corresponding hydroxylamine intermediate, $66 \%$ yield was obtained. The final yield increased to $90 \%$ in the presence of $\mathbf{f}$. Here the coordination of the coligand to the metal centre likely increases the catalyst stability toward the hydrolytic effect of water formed during the reaction.

Coordination of the coligands to the catalyst has been further demonstrated with ${ }^{51} \mathrm{~V}$ NMR spectroscopy and with the use of a chiral, enantiopure coligand, the phosphoric amide $(S, R, R)$-g (see Fig. 2). This chiral base activated the catalyst and controlled the stereochemistry of the oxidation of methyl $p$-tolyl sulfide yielding the final $(S)$ sulfoxide in quantitative yield and $14 \%$ e.e.

In order to verify that the presence of a coligand on the metal increases the electron density at the coordinated peroxide, calculations, at MP2 level using the TZVP basis set, were carried out over the model systems indicated in Scheme 4.

As expected (see Scheme 4), the $\eta^{2}$ peroxo vanadium complex is more stabilized when a stronger donor, such as trimethylamine$\mathrm{N}$-oxide, is present in the calculation. Moreover, when an electron-rich atom is coordinated, the Mulliken charge analysis confirms the increase of the electron density of the $\eta^{2}$ peroxo oxygen responsible for the oxidation process. Accordingly, the more active is the coligand the higher is the nucleophilic character of 


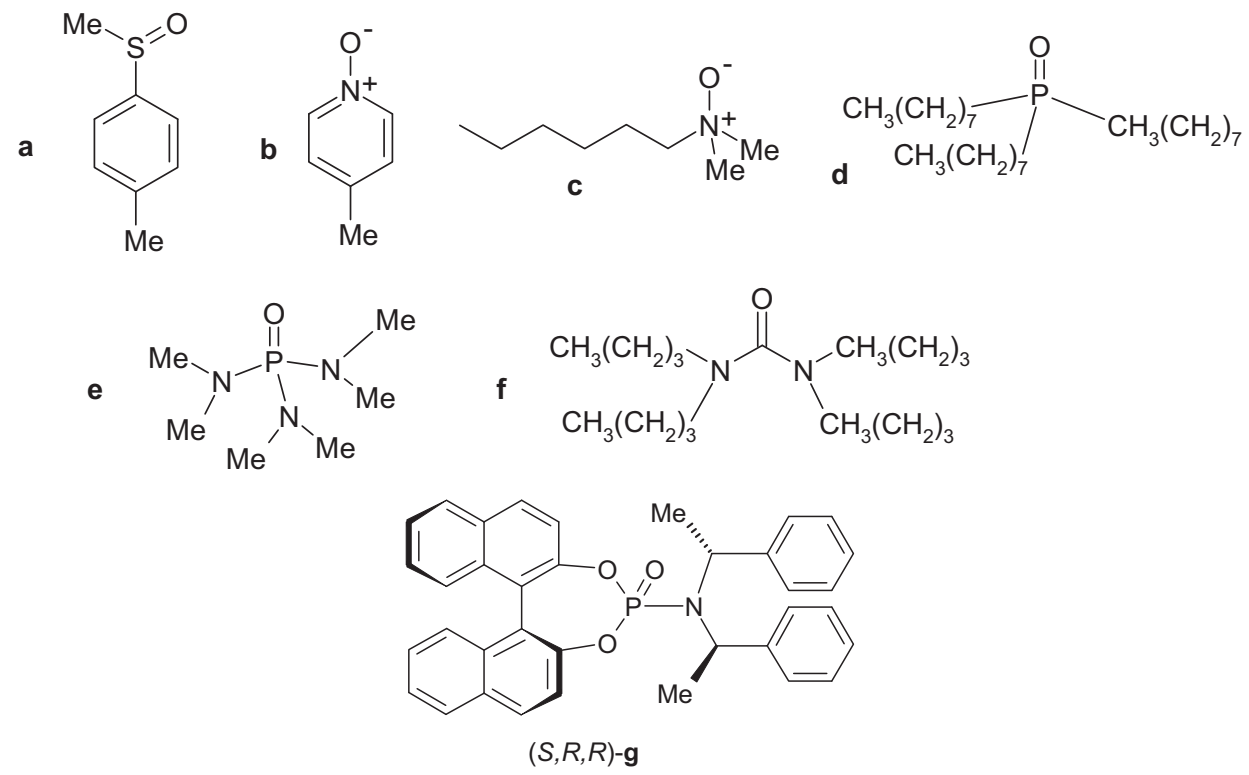

Fig. 2. Coligands employed in the VPOSS catalysed oxidations with CHP [32].

oxygen and the greater is the sulfone/sulfoxide ratio observed in the oxidation.

\subsection{Oxidation of nucleophilic substrates}

The most active $\mathrm{d}^{0}$ metal peroxo complexes toward nucleophilic substrates, like amines, phosphines, thioethers, double bonds, etc., are molybdenum, tungsten and rhenium derivatives $[19,21,25,26]$; vanadium $[23,24,75]$ and titanium $[33,34]$ catalysis is also important in particular for enantioselective processes. Numerous studies have been carried out in the last decades, with all the $\mathrm{d}^{0}$ metals involved in this type of catalysis, to clarify the mechanism of the oxygen transfer step and also to understand the transfer of chirality in enantioselective processes. Detailed discussions on these aspects are present also in the recent literature $[8,9,21,25,26,35]$.

During the years different pathways for electrophilic oxygen transfers have been suggested for the model epoxidation reaction with $\mathrm{H}_{2} \mathrm{O}_{2}$ in the presence of metal catalysis. With the aim to offer an unified vision of the possible alternatives that a peroxo complex may follow, depending on the nature of the substrate and/or the ligands, we propose the following Scheme 5 using $\mathrm{V}(\mathrm{V})$ as typical catalyst. The vanadium precursor may well be also in a lower
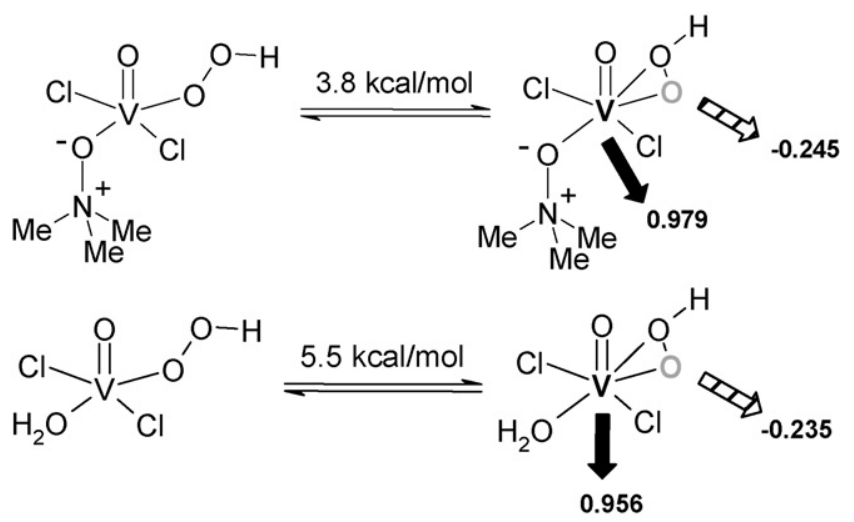

Scheme 4. Calculated energies at MP2/TZVP level for $\eta^{2}$ peroxo complex formation in the presence of $\mathrm{H}_{2} \mathrm{O}$ or trimethylamine $\mathrm{N}$-oxide. Mulliken electronic charges for the $\eta^{2}$ species are indicated for reactive oxygen (dashed arrow) and vanadium (solid arrow). oxidation state, in that case the first step is the metal oxidation, with peroxide, to $\mathrm{d}^{0}$ level, then the formation of the peroxo metal complex takes place.

Three mechanistic pathways emerged from literature data to rationalize the electrophilic epoxidation reaction $[8,9,21,22,25,26,35,36]$ and can be summarized as follow.

(i) Path A: direct attack of the substrate by the electrophilic peroxo oxygen, in analogy with the "butterfly mechanism" accepted in peracids oxidation [4], no intermediates are thus present but only a spirocyclic transition state (Sharpless-type mechanism) [33-35].

(ii) Path B: the double bond preliminarily coordinates to a vacant or labile site of the metal, therefore the nucleophilic character of the substrate is strongly reduced. Subsequently, a five membered peroxymetallacycle intermediate forms through an intramolecular 1,3-dipolar cycloaddition of the peroxo group to the coordinated alkene (Mimoun-type mechanism) $[25,26]$. Such a cyclic intermediate has been isolated, in some cases, with Pt and Pd peroxo complexes, while no direct evidence on it has been obtained with $\mathrm{d}^{0}$ peroxo species.

(iii) Path R: a radical mechanism, involving formation of a $\mathrm{V}^{\mathrm{IV}}$ superoxo specie, invoked in a reaction catalysed by a vanadium polyoxometallate (POM) [36] Occurrence of radical reactions with vanadium peroxo species in different oxidation reactions will be discussed in detail later in the paper.

Several research groups have been involved in the past in heated discussions concerning the two polar mechanisms sketched in Scheme 3. A collection of the original papers is found in diverse chapters and reviews $[8,19,21,22,24-26,35]$. Here we would like to point out that Path A mechanism of Scheme 5 is in agreement with the kinetic and spectroscopic data collected from several research groups. On the other hand a series of contradictions was encountered in fitting the experimental data into the mechanism proposed in path B, particularly with simple alkenes. Furthermore, both experimental data and theoretical calculations, dealing with $\mathrm{d}^{0}$ metals, obtained in numerous research groups have been published supporting the mechanism with the simple electrophilic oxygen atom transfer from the peroxo complex to the olefin $[9,21,35]$ More recently, very few papers appeared dealing with mecha- 


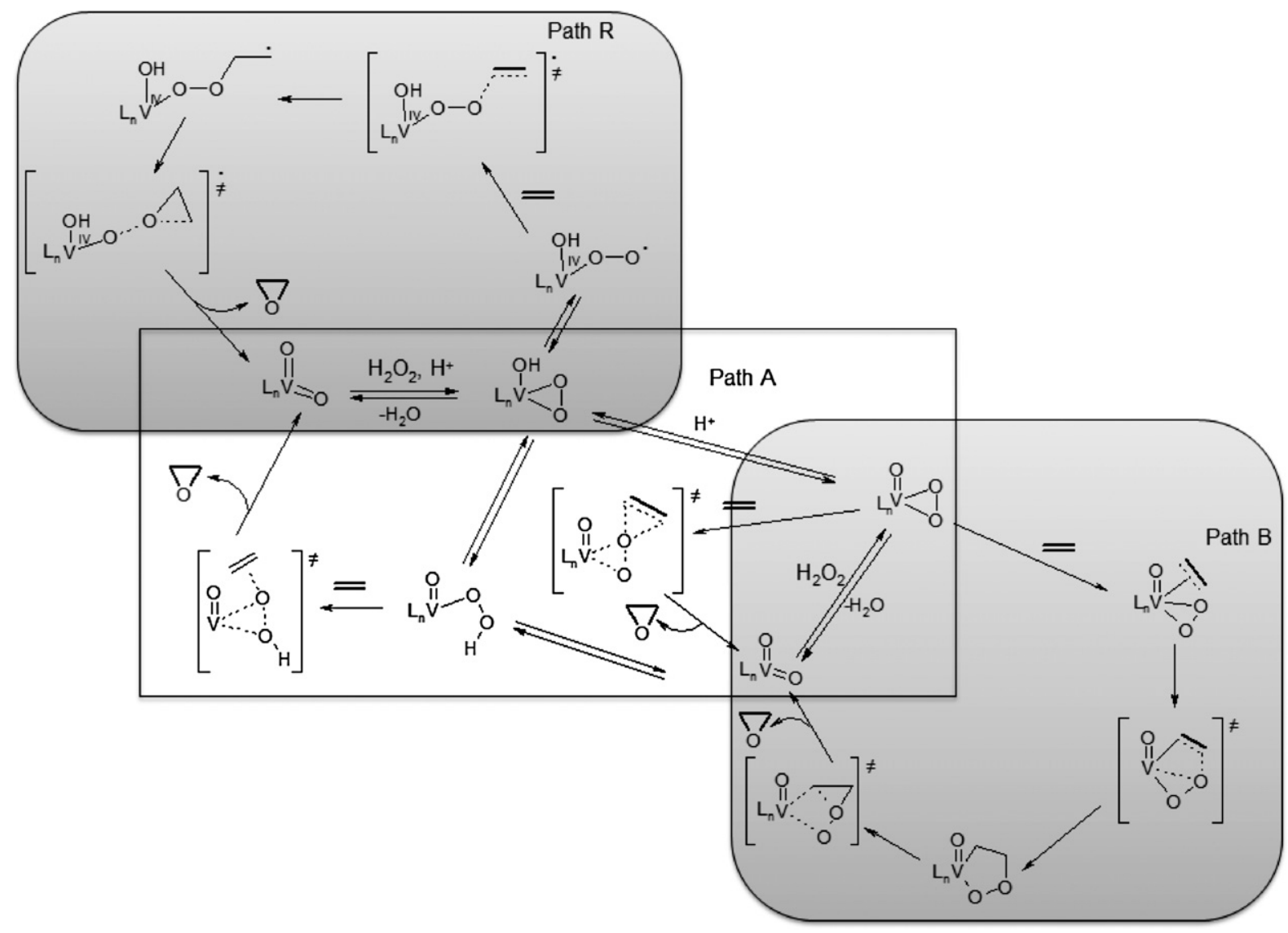

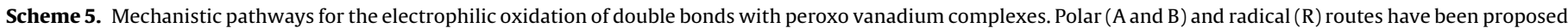
$[8,22,24-26,35,36]$.

nistic investigations related to vanadium catalysed epoxidation reactions.

Oxidation of cyclooctene and styrene, with tert-butylhydroperoxide (TBHP) as oxidant, was studied with VO[salnptn(3$\mathrm{OMe})_{2}$ ] and $\mathrm{VO}$ (hnaphntn) as catalysts, where the ligands are Schiff bases obtained from 2,2-dimethylpropanediamine and 2-hydroxy3-methoxybenzaldehyde or 2-hydroxy-1-naphthaldehyde, respectively [37].

To support the mechanism outlined in Scheme 6, a titration of the V(IV) complex with TBHP was performed by UV-Vis spectroscopy, and evidence on the formation of peroxy-vanadium(V) species has been collected.

Most of recent mechanistic studies come from Costa Pessoa's group [38], with experiments performed with V(salan) complexes accompanied by accurate quantum-chemical calculations on model

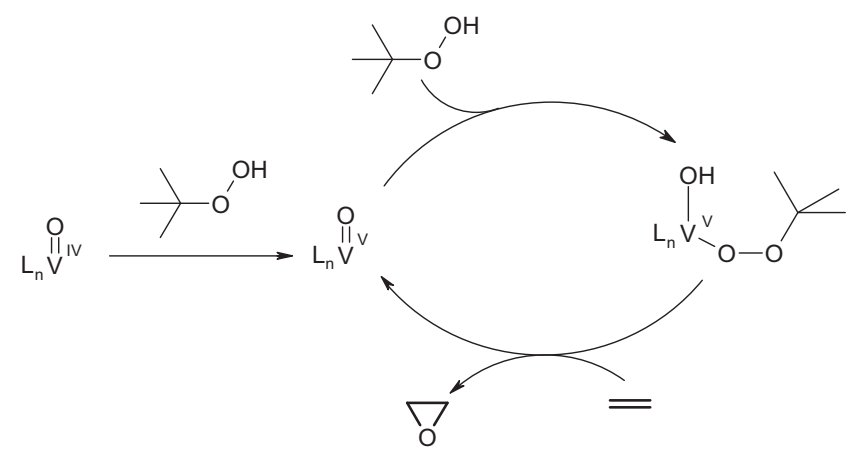

Scheme 6. Formation of peroxy $\mathrm{V}(\mathrm{V})$ species in the epoxidation of simple alkenes with TBHP [37]. complexes, using $\left(\mathrm{CH}_{2} \mathrm{NHCH}_{2} \mathrm{CH}=\mathrm{CHO}-\right)_{2}$ as ligand. Also in this paper the occurrence of cyclic intermediates appears unlikely, see Scheme 7.

Calculations were carried out at the Density Functional Theory (DFT) level, using the three-parameter hybrid exchange functional in combination with the gradient-corrected correlation functional and B3LYP. All possible geometries of complexes and structures of intermediates and transition states were taken into account for all the proposed reaction pathways. The result, sketched in Scheme 7, is straightforward since the apparent activation energy $\left(E_{\mathrm{a}}^{\mathrm{app}}\right)$ is significantly lower for the Sharpless-type mechanism than for the others, although the biradical mechanism may compete.

Same authors studied VIV containing polymer supported catalysts, see Fig. 3, in the oxidation of styrene and model alkanes [39].

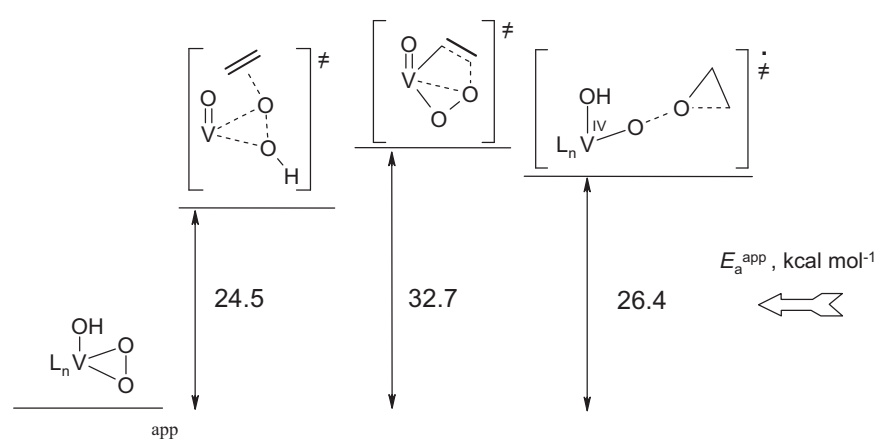

Scheme 7. Calculated $E_{\mathrm{a}}^{\mathrm{app}}$ for the possible intermediates and transition states (TS) in the $V(V)$ catalysed epoxidation of simple alkenes with $\mathrm{H}_{2} \mathrm{O}_{2}$ [38]. 


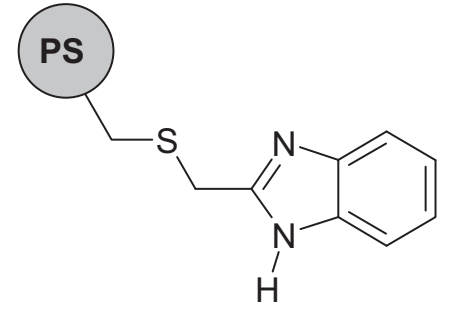

Fig. 3. Polymer supported $\mathrm{V}^{\mathrm{IV}}$ containing catalysts for oxidation of styrene and model alkanes.

Analyzing the epoxidation of styrene, oxidation of $\mathrm{V}^{\mathrm{IV}}$ to $\mathrm{V}^{\mathrm{V}}$ and subsequent formation of peroxo derivative was observed. On the other hand, also in this case, no straightforward evidence of coordination of the substrate was obtained, at odd with the analogous $\mathrm{Cu}$ supported catalysts.

The mechanistic pathways collated in Scheme 5 can be invoked also in the case of other substrates such as the more nucleophilic thioethers. With this substrates, formation of the peroxometallacyclic intermediate is even more doubtful because of the strain of a four members ring intermediate [8,21].

The oxidation of prochiral thioethers to non-racemic sulfoxides is one of the most important reactions in the field of asymmetric synthesis. A comprehension of the mechanistic pathways operating in the metal catalysed version of such process is clearly fundamental in order to obtain effective and selective procedure. Reviews, concerning the synthetic aspects of enantioselective synthesis of sulfoxides, appeared recently [40,41]. In those papers the very many chiral ligands used in the vanadium catalysed version of the oxidation with peroxides, mainly variously substituted Schiff bases [42], are collected and the structural features are also discussed.

Bryliakov and Talsi performed several detailed spectroscopic studies to elucidate the solution structures of peroxo and peroxy species formed upon reaction of vanadium precursors, chiral ligands (mostly Schiff bases) and $\mathrm{H}_{2} \mathrm{O}_{2}$ or TBHP [43]. The presence of an oxo vanadium diligated species as active catalyst in the oxidation of di-tert-butyl disulfide with $\mathrm{H}_{2} \mathrm{O}_{2}$ has been proposed by Ellman, see Fig. 4 [44].

In a similar system, a detailed computational study, with a $\mathrm{QM} / \mathrm{MM}$ method, has been carried out in order to clarify the mechanism of the enantioselective oxidation of di-tert-butyl disulfide with $\mathrm{VO}(\mathrm{OOH}) \mathrm{L}$, L being a bulky Schiff base with different substituents in the aromatic ring [45]. The in silico data reproduced reasonably well the experimental ones. Variation of the e.e. as a function of the substituents has been explained on the basis of the presence of two different forms of the active oxidant.

A very detailed discussion dedicated to the mechanistic steps involved in the oxidation of thioethers and disulfides with peroxides in the presence of vanadium complexes has been presented by Rehder in his recent book [3]. The seminal works, both experimental and theoretical, by Pecoraro and his group allowed to elucidate

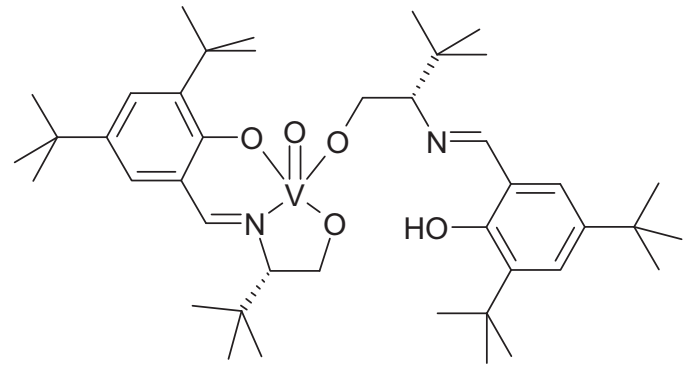

Fig. 4. Ellman catalyst for oxidation of di-tert-butyl disulfide with $\mathrm{H}_{2} \mathrm{O}_{2}$ [44].

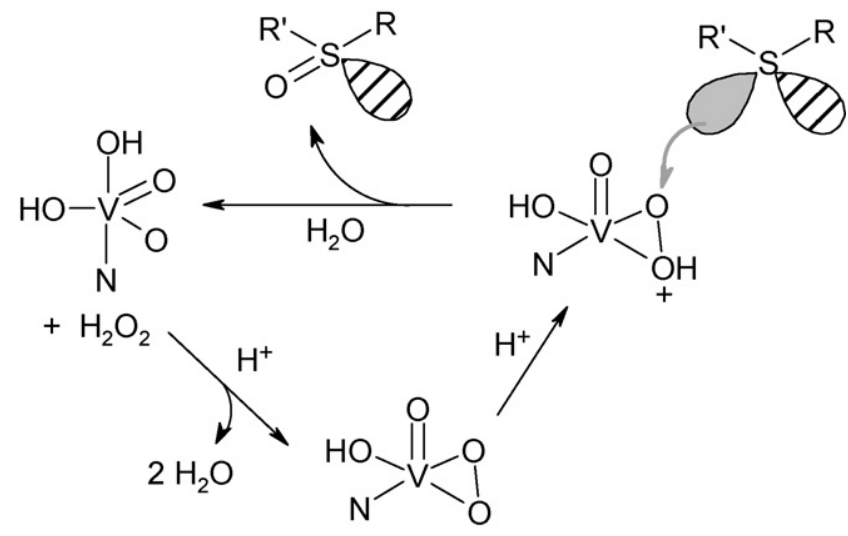

Scheme 8. Key steps in the thioether oxidation with protonated vanadium peroxo species $[47,48]$.

the significance of protonation of the peroxidic intermediate in such reactions (Scheme 8).

Pecoraro demonstrated, using the $\mathrm{K}\left[\mathrm{VO}\left(\mathrm{O}_{2}\right)\right.$ heida] [46] (heida = hydroxyethyliminodiacetic acid) complex, that the reaction of a nucleophilic substrate, i.e. halides or thioethers, takes place after protonation of a peroxo oxygen to form an hydroperoxo intermediate.

The location of the protonation site, i.e. the $\eta^{2}$-peroxo ligand, has been identified with experimental spectroscopy [47] (XANES) and DFT calculations on the model compound [ $\mathrm{VO}\left(\mathrm{O}_{2}\right)$ heida $]^{-}$[48]. Those results support also the hypothesis of a key role played by a hydroperoxo intermediate in the catalytic cycle of VHalPOs functional model. In fact the same research group investigated, with DFT calculations, the structural, electronic, and catalytic properties of the vanadium cofactor in VHalPOs [49,50], as a function of environment and protonation state [51] indicating the important role of protonation in cofactor activation.

Other ligands have been also prepared, purposely, in order to model the active centre of the VHPO and its sulfoxidation activity. In particular, chiral amino alcohols derived from glycine ( $L$ and $\mathrm{L}^{\prime \prime}$ ) and sarcosine $\left(\mathrm{L}^{\prime}\right)$ were chosen, see ligands indicated in Fig. 5.

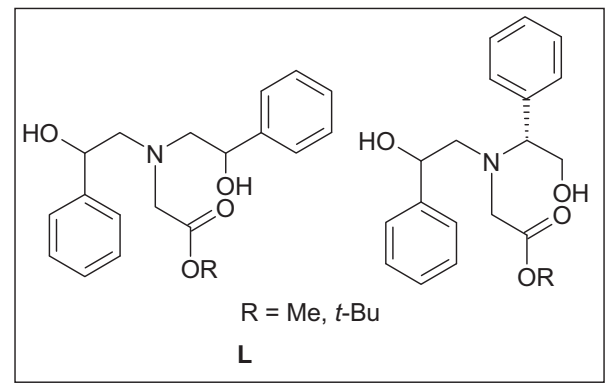<smiles>[R]OC(=O)CN([R])CC(O)c1ccccc1</smiles>

$\mathrm{R}=t-\mathrm{Bu}, \mathrm{R}^{\prime}=\mathrm{H}$ $\mathrm{R}=\mathrm{R}^{\prime}=\mathrm{Me}$ $\mathrm{R}=\mathrm{H}, \mathrm{R}^{\prime}=\mathrm{Me}$ $\mathbf{L}^{\prime}$

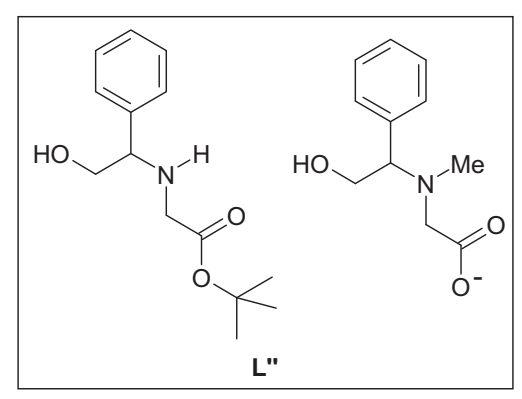

Fig. 5. Glycine and sarcosine derived ligands active in the vanadium catalysed enantioselective thioethers oxidation with CHP [52]. 


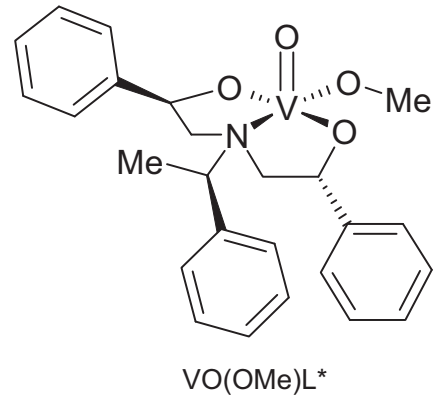

Fig. 6. Chiral vanadium oxo complex active in the enantioselective thioethers oxidation with CHP [53].

The preformed complexes and the in situ systems (ligand $\left.+\mathrm{VO}(\mathrm{OiPr})_{3}\right)$ were active in the catalysed oxidation by $\mathrm{CHP}$ of prochiral sulfides to chiral sulfoxides and, in most cases, to some sulfone [52]. The most efficient system with respect to selectivity ( $100 \%$ of sulfoxide and turn-over frequency up to $60 \mathrm{~mol}$ of sulfoxide $\mathrm{mol}^{-1}$ of catalyst $\mathrm{h}^{-1}$ ) was obtained using the preformed $\mathrm{VO}(\mathrm{OiPr}) \mathbf{L}(\mathrm{R}=t-\mathrm{Bu})$ complex, while the highest enantioselectivity (38\% e.e.) was obtained preparing that catalyst in situ. The low enantioselection observed has been explained on the basis of the fluxionality, detected with ${ }^{51} \mathrm{~V}$ NMR, of the $[\mathrm{VO}(\mathrm{O} i \mathrm{Pr}) \mathbf{L}]$ complex and of the active oxidant $[\mathrm{VO}(\mathrm{OOcumyl}) \mathbf{L}]$ formed in the course of the reaction. DFT calculations indicated that the organic ligand coordinates, in an end-on fashion, preferentially in the axial position. Deprotection of the ligand provided an additional coordinating function, which renders the catalyst more rigid, and drastically reduced the yields.

The sulfide peroxidase activity has been also modelled with a vanadium $(\mathrm{V})$ complex, $\mathrm{VO}(\mathrm{OMe}) \mathrm{L}^{*}$ (see Fig. 6), containing a coordination environment, similar to that found in the native enzymes, obtained with a ligand derived from a trichiral aminobis(alcohol) [53]. The e.e. in the non-optimized oxidation of methyl-p-tolylsulfide by $\mathrm{CHP}$ in the presence of $\mathrm{VO}(\mathrm{OMe}) \mathrm{L}^{*}$ is $25 \%$ for the $R$-sulfoxide with the $R, R, R$-ligand, some sulfone being also formed. The same results were obtained with a mixture of the ligand and $\left[\mathrm{VO}(\mathrm{OiPr})_{3}\right]$ as catalytic system; in this latter case, quite surprisingly, the reaction is faster.

The kinetic behaviour observed is consistent with the typical oxidation mechanism with vanadium peroxo compounds.

Clear evidence, pointing to an electrophilic oxygen transfer process toward alkyl and aryl thioethers, has been, once more, obtained in a very efficient catalytic system which employs $C_{3}$-symmetric vanadium(V) amine triphenolate complexes (see Fig. 6) and $\mathrm{H}_{2} \mathrm{O}_{2}$ [54]. In particular, selectivity toward formation of sulfoxides is higher than $97 \%$, dialkyl sulfides are oxidized faster that the corresponding alkyl aryl derivatives, and electron withdrawing groups eventually present in the aromatic rings cause the substrate to be much less reactive.

This catalyst exhibits very high efficiency (turn-over numbers TON $=9900$ in $4 \mathrm{~h}$, turn-over frequency TOF up to 8000) thus being very effective also in mimicking the activity of VHalPO enzymes. Their behaviour in the oxidation of halides will be discussed later in the paper.
Asymmetric oxidation of sulfides and kinetic resolution of sulfoxides with hydrogen peroxide, catalysed by a salan-vanadium catalyst have been obtained [55]. The procedure appears to be very efficient for the preparation of chiral sulfoxides in good chemical yields and excellent enantiomeric purity. Interestingly an important feature of the system is the production of chiral sulfoxides in higher e.e. and opposite enantioselection in comparison with that of the corresponding salen system. Moreover, the enantioselectivity of the asymmetric oxidation of sulfides is not enhanced by a concomitant kinetic resolution of the corresponding chiral sulfoxides. The $R$ and $S$ sulfoxides can be thus obtained by the enantioselective oxidation of sulfides or via kinetic resolution of sulfoxides, respectively, catalysed by the same salan-vanadium catalyst. The authors suggest an oxidation mechanism where the sulfide coordinates to the vanadium oxo oxygen and only subsequently $\mathrm{H}_{2} \mathrm{O}_{2}$ becomes involved in order to break the intermediate and re-oxidize the vanadium centre. However no definite proof of the mechanism were offered. Furthermore, in repeating those experiments other groups were unable to obtain the same e.e. [56, 38a].

Also Espenson offered mechanistic studies (among other experimental data, Hammett plot with a negative $\rho$ values of -0.83 ) in agreement with the nucleophilic attack of the thioethers on the peroxo oxygen of a diperoxo species formed in acidic aqueous acetonitrile, in the presence of large excesses of $\mathrm{H}_{2} \mathrm{O}_{2}$ [57]. Interestingly, the authors suggest the vanadium diperoxo anion as active oxidant, which should be, because of the negative charge, a weaker electrophile as compared with the monoperoxo complex.

\subsection{Radical oxidations}

Radical reactions [58-60] of peroxo metal complexes have been observed in the oxidation of thioethers [61], alkenes [62], aromatics [62-64] and alcohols [65]. The major mechanistic studies carried out in this context are related to the chemistry of a monoperoxo vanadium picolinate complex, $\mathrm{VO}\left(\mathrm{O}_{2}\right)$ pic, synthesized by Mimoun et al. in 1983 [62]. Reviews reporting the radical reactivity of vanadium peroxides in general, and in particular of $\mathrm{VO}\left(\mathrm{O}_{2}\right)$ pic, have been offered earlier by Butler et al. [22] and more recently also from our groups $[8,9,24]$, therefore we will mention here only the most peculiar aspects of such mechanisms.

On the basis of kinetic studies the mechanism, indicated in Scheme 9, has been proposed for the radical oxidation of thioether with $\operatorname{VO}\left(\mathrm{O}_{2}\right)$ pic [61]. The key step is the formation, within the solvent cage, of a radical cation-anion pair. The picolinate ligand reduces the electrophilicity of the peroxo complex, thus allowing the competitive radical process to take place.

Further evidence on the occurrence of radical reactions in the oxidation of variously substituted benzyl thiols and benzyl phenyl sulfides with $\mathrm{VO}\left(\mathrm{O}_{2}\right)$ pic, in $\mathrm{CH}_{3} \mathrm{CN}$, has also been obtained recently [66]. The effect of the substituents suggests an electrophilic nature of the radical oxidant, as already observed in previous studies [64].

The original work, where the synthesis and the reactivity of $\mathrm{VO}\left(\mathrm{O}_{2}\right)$ pic were reported [62], claims that such species perform unselective epoxidation reactions. The mechanism proposed involves an homolytic rupture of one metal-peroxo oxygen bond to

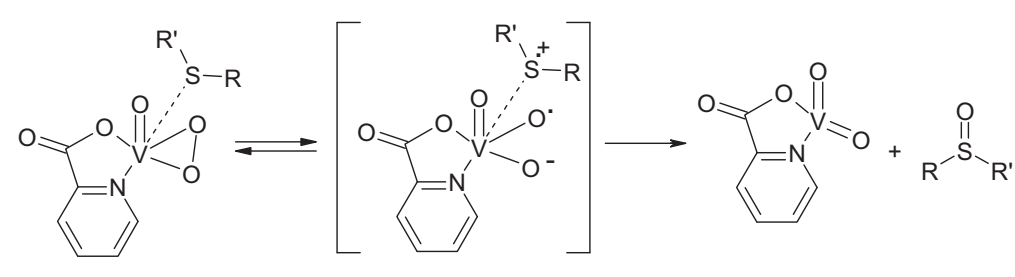

Scheme 9. Radical mechanism for thioethers oxidation with $\operatorname{VO}\left(\mathrm{O}_{2}\right)$ pic [61]. 
produce the active oxidant, see Scheme 10 . A closely related mechanism has been suggested also for the hydroxylation of aromatic substrates [62]. In Scheme 10 both reactions are reported indicating the occurrence of the same active species.

One of the most important features of the radical reactivity of peroxo vanadium species is the simultaneous vanadium catalysed decomposition of $\mathrm{H}_{2} \mathrm{O}_{2}$ to form dioxygen, reaction that explicitly is not considered in the Mimoun reaction scheme.

When the hydroxylation of arenes has been studied in more detail, on the basis of kinetic and spectroscopic studies, a much more complicated mechanism has been proposed [64,67].

The expected active intermediate is a radical anion formed upon interaction of two molecules of the vanadium peroxo complex. The sequence of the various steps, also those accounting for decomposition of the peroxidic species to form dioxygen, is indicated in Scheme 11.

$\mathrm{VO}\left(\mathrm{O}_{2}\right)$ pic is a quite stable species in protic solvents, while it rapidly decomposes in $\mathrm{CH}_{3} \mathrm{CN}$ forming a yellow insoluble dimeric complex together with evolution of molecular oxygen. If it is allowed to decompose in the presence of benzene, phenol is formed in fair yield at room temperature. In both cases the kinetic behaviour is autocatalytic, typical of radical chain mechanisms. We have demonstrated, investigating the reactivity of picolinate vanadium peroxo complex in various solvents and in the presence of both one-electron donors and radical traps, that the active species, formally a radical-anion derivative, is produced via the one electron reduction of the picolinate mono peroxo complex. Such initiation process occurs in non coordinating solvents whereas it

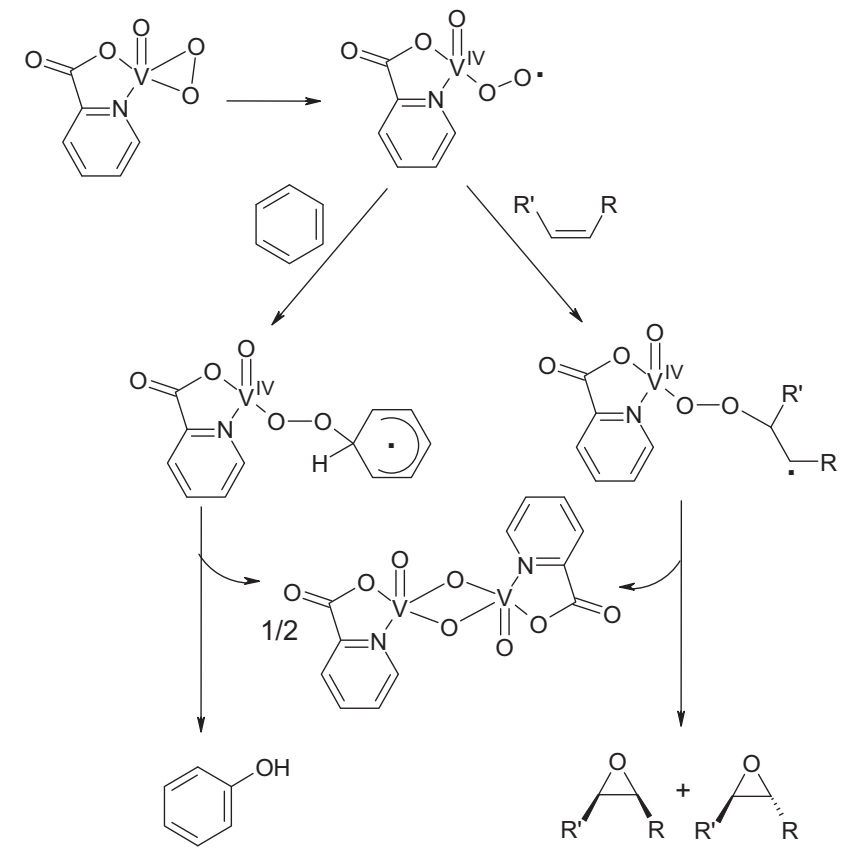

Scheme 10. Major steps in the reactions of $\mathrm{VO}\left(\mathrm{O}_{2}\right)$ pic with alkenes and arenes as proposed by Mimoun et al. [62].

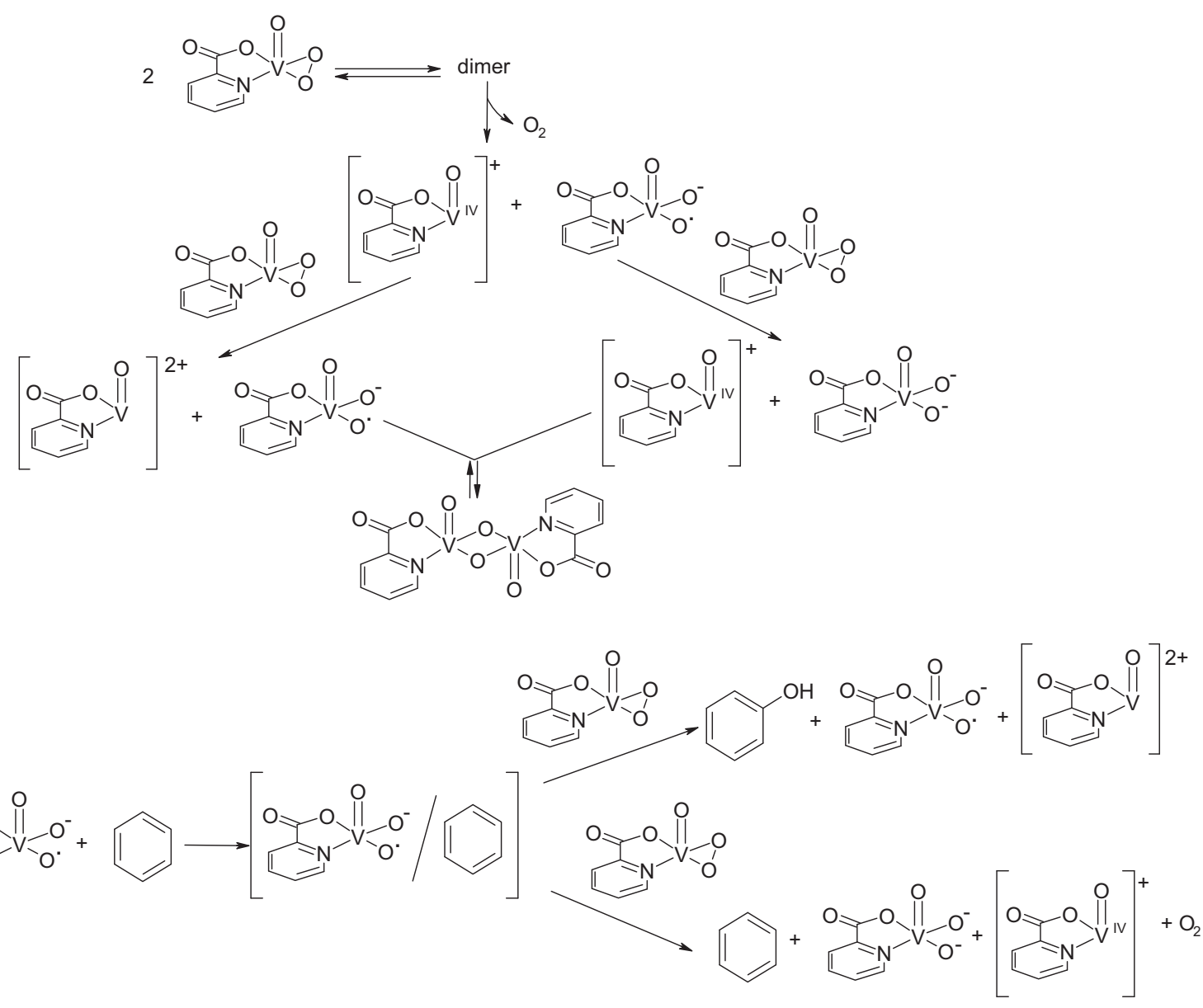

Scheme 11. Proposed reaction mechanism for benzene hydroxylation with $\mathrm{VO}\left(\mathrm{O}_{2}\right)$ pic $[64,67]$. 
is almost suppressed in $\mathrm{CH}_{3} \mathrm{OH}$, water or DMF. Subsequently, with the rather complex reaction mechanism indicated in Scheme 11, all the observed competitive reactions: peroxo complex decomposition, benzene hydroxylation and dioxygen formation, take place. In that quite long study, the identification of intermediates has been very complex and therefore the understanding of the reactivity was highly gratifying. The work, certainly quite old, still maintains its interest in consideration of the significance of benzene hydroxylation process.

Recently, direct hydroxylation of aromatic hydrocarbons, i.e. benzene, toluene and anisole, with hydrogen peroxide in acetonitrile has been achieved in the presence of heterogeneous vanadium containing catalysts. The most effective catalyst among those tested is a vanadyl tetraphenoxyphtalocyanine, which maintained its catalytic activity even after four reaction cycles [68]. The observation of such reactivity, particularly with heterogeneous catalysts, is a very important step forward more sustainable protocols for arene hydroxylation.

Interestingly, benzene and cyclohexene hydroxylation with $\mathrm{H}_{2} \mathrm{O}_{2}$ has been performed in highly acid conditions [69], where the necessary peroxide is formed in situ via a palladium catalysed reaction from dihydrogen and dioxygen, and the subsequent hydroxylation reaction is vanadium catalysed. Comparison of the results obtained with in situ formation of $\mathrm{H}_{2} \mathrm{O}_{2}$ against those observed with slow external addition of the peroxide, indicates that the former methodology leads to higher selectivity. The study presents also mechanistic proofs favoring the role of $\mathrm{H}_{2} \mathrm{O}_{2}$ as oxidant of the acetylacetonate containing $\mathrm{V}^{\mathrm{III}}$ precursor to a $\mathrm{V}^{\mathrm{V}}$ dihydroxo species. The latter is proposed as the one electron oxidant of the aromatic substrate to form a radical cation which then evolves to the products. Even if the concentration of the peroxide is kept very low during the entire process, the occurrence in the reaction pathway of a $V^{I I I}$ peroxospecies and the absence of the corresponding $\mathrm{V}^{\mathrm{V}}$ derivative appears to be, at least, questionable $[8,9,21]$.

Several papers dedicated to the reactivity of peroxovanadium complexes toward alkanes have been published by Pombeiro and Shul'pin [70]. In their system the presence of pyrazine-2carboxylic acid (pca) is mandatory in order to obtain the active

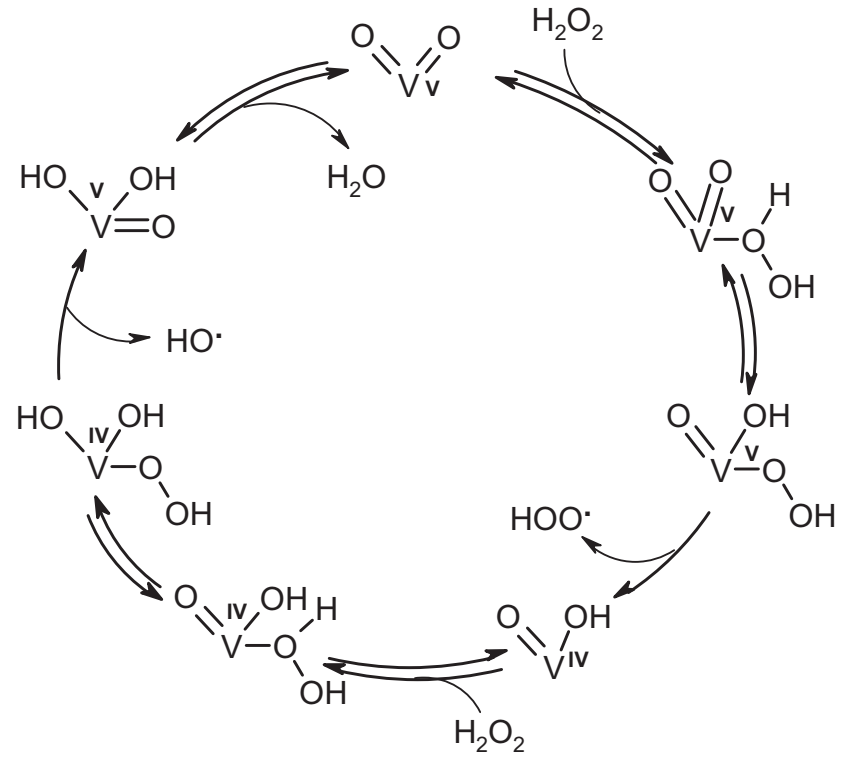

Scheme 12. Proposed simplified catalytic cycle for the vanadium assisted hydroxyl and hydroperoxyl radicals formation in the oxidation of hydrocarbons [70,71].

complex. Furthermore, on the basis of several pieces of evidence, they proposed the formation of $\mathrm{HO}^{\bullet}$ and $\mathrm{HOO}^{\bullet}$ radicals as reactive species toward the organic substrates. In Scheme 12 the key steps proposed for such process are indicated in a simplified version [71].

In the meticulous study [70], by reason of kinetic, spectroscopic and theoretical DFT data, several details of the mechanism have been elucidated. In particular, the authors focused on the energy of the $\mathrm{H}$-transfer step from the coordinated $\mathrm{HOOH}$ to the $\mathrm{V}=\mathrm{O}$ bond and compared two pathways. The first is the initially proposed so called "robot's arm" mechanism with a 4-membered transition state [72], where the hydrogen transfer from a coordinated $\mathrm{H}_{2} \mathrm{O}_{2}$ molecule to the oxygen atom of a pca ligand at the vanadium centre is the rate-limiting step. The second one is the "water assisted"

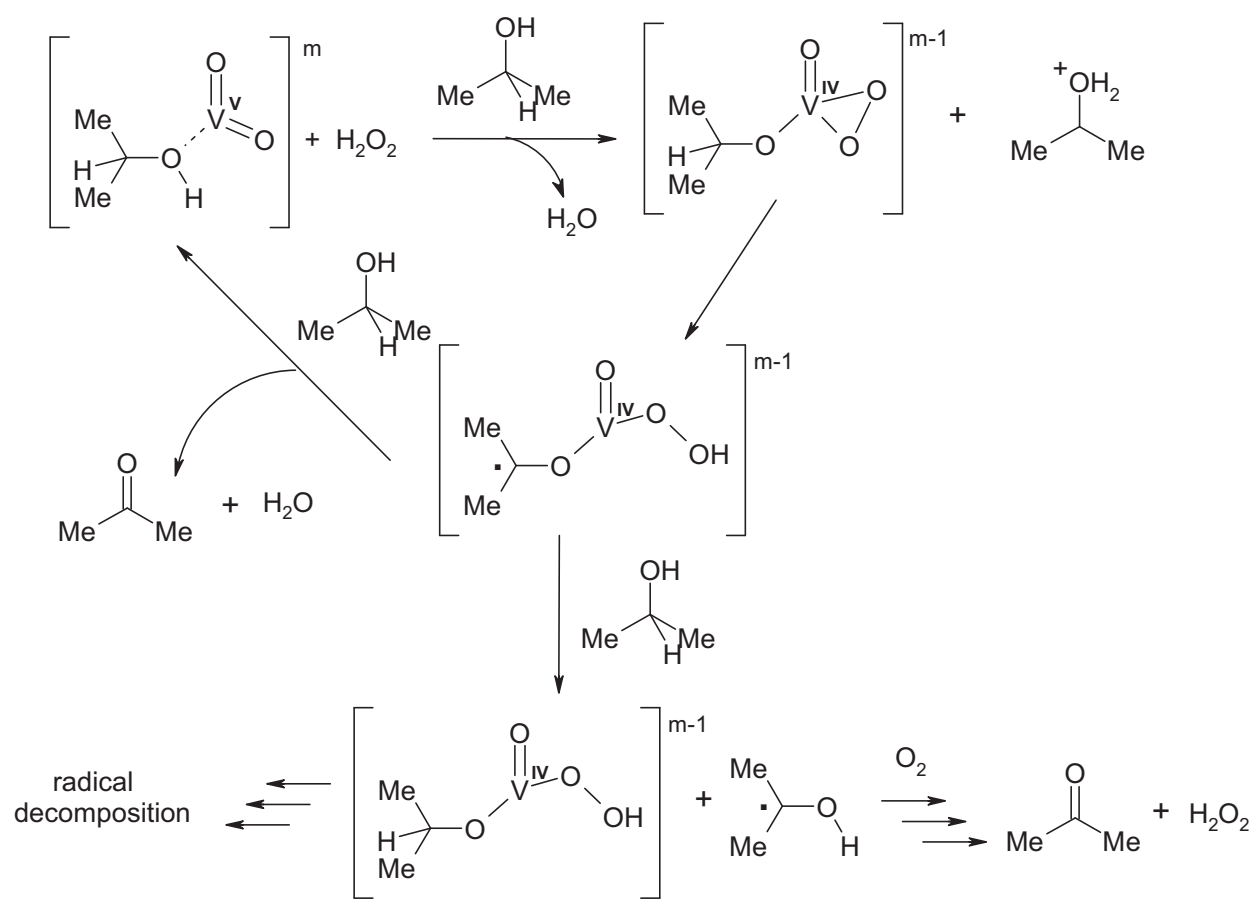

Scheme 13. Radical chain mechanism for the oxidation of 2-propanol with peroxovanadate. 


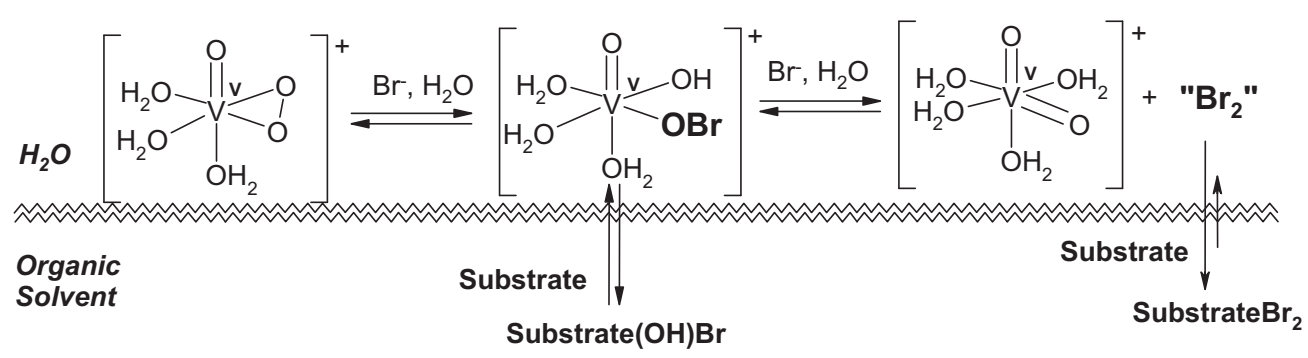

Scheme 14. Proposed intermediates in the two-phase $V(V)$ catalysed oxybromination reaction.

path with a 6-membered transition state. On the basis of DFT calculations, the latter mechanism appears to be highly favoured [70]. For more details on this topic interested readers are referred to the original papers [70,72].

Analogous theoretical results were obtained with $\mathrm{MeReO}_{3}$ catalyst; in particular with this metal the calculated activation energy of the radical formation (ca. $17 \mathrm{kcal} / \mathrm{mol}$ ) is very close to that experimentally observed with vanadium oxo derivatives $(17 \pm 2 \mathrm{kcal} / \mathrm{mol})$, on this basis the authors extended such mechanism also to the Re mediated processes [71].

Alkoxo monoperoxo vanadium complexes are also efficient oxidants of the alcoholic function $[65,73,74]$ with a radical chain mechanism indicated in Scheme 13 in the case of 2-propanol.

Interestingly, in the course of the oxidation, together with acetone, also $\mathrm{H}_{2} \mathrm{O}_{2}$ is formed and accumulated in solution; its concentration during the reaction displays an oscillating behaviour.

\subsection{Bromination reactions}

A good deal of work has been devoted to the comprehension of the mechanistic details of a model system for the VHalPO reactivity based on a two-phase system. Combining reactivity analysis with spectroscopic techniques, mainly ${ }^{51} \mathrm{~V}$ NMR [9], we have been able to identify monoperoxo vanadium complexes as the competent oxidant of bromide ion, while the diperoxo derivative likely acts as a reservoir for the active oxidant. When alkenes are the substrates, two products are usually observed: bromohydrin and dibromide [16]. To note, the reaction is typically characterized by a good degree of selectivity toward formation of the bromo- hydrin while, in similar conditions, other classical brominating reagents produce selectively dibromide. Moreover, we observed the dependence of products yields on the rate of stirring. Evidence has been obtained for substrate coordination, as indicated by the preferential formation of bromohydrin from more nucleophilic substrates. Interestingly, Hammett correlations indicate two parallel processes, therefore our mechanistic proposal includes two intermediates: i.e. a vanadium bound hypobromite ion, responsible for the formation of bromohydrin and the second one, bromine, in charge of the formation of dibromo compounds, see Scheme 14 $[11,16]$.

The occurrence of the vanadium bound hypobromite-like intermediate has been substantiated with spectrometric experiments [16]. The mechanistic idea is that such species should be directly involved in the " $\mathrm{Br}^{+}$" transfer process or, at least, it is one of the active species in the bromination process [75]. Calculations related to the involvement of similar species, where the equatorial peroxo oxygen is protonated and the $\mathrm{Br}^{-}$is prone to coordinate the other peroxidic oxygen, has been recently published by Pecoraro's group [49]. Also Littlechild et al. [7] proposes the involvement of $\mathrm{V}-\mathrm{O}-\mathrm{Br}$ species in the catalytic cycle of $\mathrm{VBrPO}$ enzymes (see Scheme 1).

The involvement of a $\mathrm{V}(\mathrm{V})$ containing brominating species has been confirmed in the two-phase reaction with adamantylideneadamantane, a substrate containing an hindered double bond, which, in standard bromination process, does not go further after the formation of bromiranium ion. In such a process a salt containing the bromiranium cation together with the vanadate anion has been isolated and fully characterized [76].

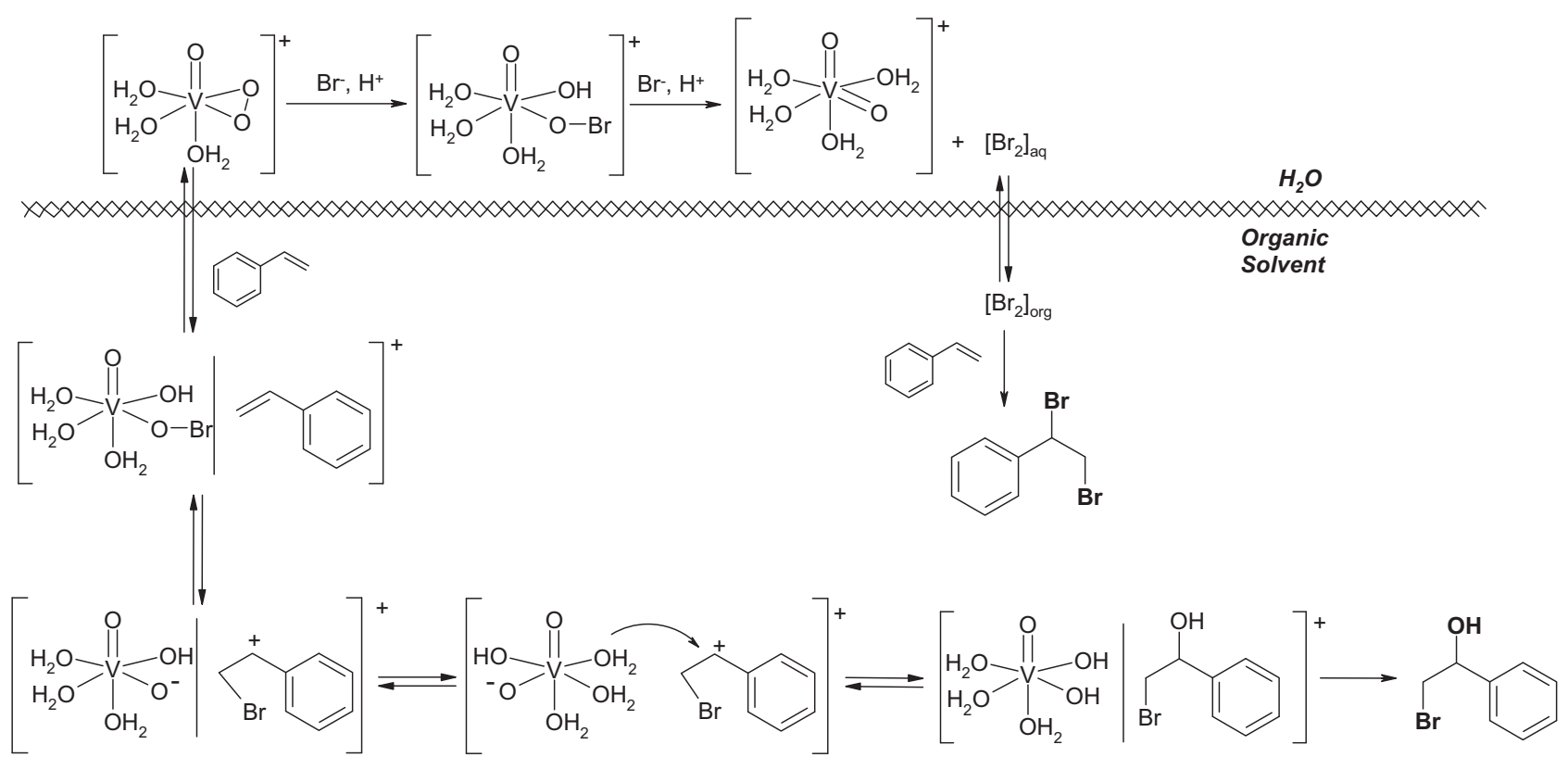

Scheme 15. Key-steps in the two-phase V-catalysed oxybromination of double bonds. 
The oxybromination reaction with styrene, see Eq. (2), has been chosen as model [24].<smiles>OC(CBr)c1ccccc1</smiles>

On the basis of the experimental data, ab initio calculations and ESI-MS experiments, a mechanistic scheme has been proposed (see Scheme 15), where the two products are obtained following two parallel pathways, both starting from the vanadium-hypobromito intermediate, generated by the reaction between monoperoxo vanadium and bromide ion.

Such species can then react with another bromide ion to give $\mathrm{Br}_{2}$, responsible for the formation of dibrominated product; on the other hand $\mathrm{Br}^{+}$can be transferred to the substrate to form the cationic intermediate. Subsequent nucleophilic attack by a vanadium bound water molecule forms the bromohydrin.

An analogous reaction has been studied, for the first time, with alkynes, the products formed are indicated in the following Eq. (3) data support the idea that in the ionic environment a higher concentration of the active species is possible, while a slower escape from the organized solvent cage assists the reaction between the bromiranium intermediate and a water molecule bound to vanadium. The consequence is a more selective and faster formation of bromohydrins. In this respect data obtained with trans-stilbene in molecular solvent, i.e. formation of both stereoisomers of the halohydrin, suggest that the 2 more stable carbocation is formed, while in ILs formation of bromiranium ion is preferred.

The related mechanism, suggested for alkynes [78] explains the experimental results obtained using hydrophobic ILs quite well. In fact, the lower yield of 1,2-dibromostyrene on going from dichloromethane to butyl methyl imidazolium hexafluorophosphate $\left[\mathrm{bmimPF}_{6}\right.$ ] can be derived from an inhibited formation of molecular bromine in the ionic medium, where the functionalization of the substrate should take place. Moreover, the internal structure of IL may help in keeping the reactive species within the organized solvent cage, thus rendering the reaction faster [78].

The activity of $\mathrm{C}_{3}$-symmetric amine triphenolate $\mathrm{V}(\mathrm{V})$ complexes [54] (see Fig. 7) was tested also in halogenation of 1,3,5-trimethoxybenzene, with $\mathrm{H}_{2} \mathrm{O}_{2}$ and $\mathrm{Bu}_{4} \mathrm{~N}^{+}$bromide or chlo-<smiles>C#Cc1ccccc1</smiles><smiles>CC(C)[PH2+]Br</smiles><smiles>BrC=C(Br)c1ccccc1</smiles>

The synthetic aspects of this procedure have been reviewed recently [24] and here we would like only to remind that a reaction mechanism, very similar to that invoked for alkenes, has been proposed [77].

The two-phase procedure has been implemented in a more sustainable method via substitution of the chlorinated organic solvents with ionic liquids. When the model reactions with alkenes have been carried out in hydrophobic ionic liquids, better yields and selectivity toward bromohydrin were observed even with lower amounts of catalyst. Provided that our reaction mechanism still holds in ILs [77,78], these improvements can be ascribed to the ionic environment which, likely, from one side disfavours the transfer of bromine in the IL phase where the substrate is dissolved and at the same time allows an easier phase transfer of the vanadium containing catalytic active species from water. Furthermore, the selectivity<smiles></smiles>

ride as halogen sources. Under the classical reaction conditions used for VHalPO mimicking process [4] the bromination proceeds almost instantaneously to the monobrominated product with almost quantitative yield. The presence of acid is necessary as expected on the basis of the accepted reaction mechanism already indicated in Scheme 8 for thioethers.

The catalyst amount could be decreased down to $0.05 \%$ with a TON up to 1260 . The importance of the amine triphenolate ligands has been proven by comparison with the analogous reactions performed in the presence of $\mathrm{VO}(\mathrm{acac})_{2}$ where lower rates and conversions were obtained [54]. Chlorination of 1,3,5trimethoxybenzene was slowly obtained in similar conditions. Therefore, mononuclear $\mathrm{C}_{3}$-vanadium $(\mathrm{V})$ amine triphenolate complexes appear to be good structural and functional models of<smiles>[R]C([R])=CCC([R])C([R])O</smiles><smiles>Oc1ccccc1/C=N/c1ccccc1O</smiles><smiles>CC(C)(C)c1cc(/C=N/c2ccccc2O)c(O)c(C(C)(C)C)c1</smiles><smiles>Cc1ncc(CO)c(/C=N/c2ccccc2O)c1O</smiles><smiles>CSCC[C@H](CO)N=Cc1cc(C(C)(C)C)cc(C(C)(C)C)c1O</smiles><smiles>CS(=O)CC[C@H](CO)N=Cc1cc(C(C)(C)C)cc(Br)c1O</smiles><smiles>CC(C)[C@H](CO)N=Cc1cc(C(C)(C)C)cc(C(C)(C)C)c1O</smiles><smiles>CC(C)(C)c1cc(/C=N/[C@@H]([18CH2])CO)c(O)c(C(C)(C)C)c1</smiles>

Scheme 16. Vanadium catalysed in situ generation of bromine to form functionalized cyclic ethers [79]. 


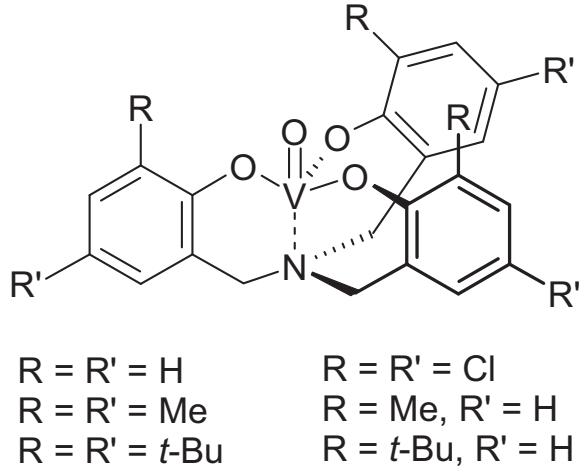

Fig. 7. $C_{3}$-symmetric amine triphenolate $V(V)$ complexes.

VHalPOs, effectively catalysing the oxidation with hydrogen peroxide of thioethers and bromide ions.

A synthetically interesting application of a bromination reaction starting from bromide ions was recently reported by Hartung and co-workers [79]. They reported that a series of Schiff base containing vanadium derivatives are good catalysts in the synthesis of functionalized cyclic ethers, see Scheme 16. Even though the primary oxidant is TBHP, a less sustainable peroxide if compared to $\mathrm{H}_{2} \mathrm{O}_{2}$, formation of interesting products is easily obtained with good yields and selectivity. Also the enantioselective version of the reaction has been reported. From the mechanistic point of view the authors indicate that the role of vanadium is only in the step of bromide ion oxidation to form bromine. The subsequent formation of the brominated cyclic products is due to the $\mathrm{Br}_{2}$ formed in steady state concentration.

\section{Conclusions}

In this short review, mainly an account of our work, of recent achievements of vanadium catalysed oxidation reactions we intended to display the significance of mechanistic studies when applied to catalysis. As, hopefully, clearly indicated in the different schemes, vanadium peroxo species may react with different substrates with different mechanisms, both polar or radical. The elucidation of the different steps has been often difficult and no clear example of structure/reactivity correlation has been obtained so far.

We also hope that this approach will stimulate more researchers to explore the wide range of vanadium applications in chemistry, which span from organic synthesis, biochemical processes, medicinal chemistry, to inorganic chemistry, materials and other interesting subjects.

\section{Acknowledgements}

COST D40 Action is gratefully acknowledged for promoting the interaction between the two research groups.

\section{References}

[1] D. Rehder, Org. Biomol. Chem. 6 (2008) 957, and references cited therein.

[2] D.C. Crans, J.J. Smee, E. Gaidamauskas, L. Yang, Chem. Rev. 104 (2004) 849, and references cited therein.

[3] D. Rehder, Bioinorganic Vanadium Chemistry, John Wiley \& Sons Ltd, 2008.

[4] See as few examples;

(a) A. Butler, A.H. Baldwin, Structure and Bonding - Metal sites in Proteins and Models, vol. 89, Springer Verlag, Berlin-Heidelberg/Dordrecht, 1997, and references cited therein;

(b) V. Pecoraro, C. Slebodnick, B. Hamstra, in: D.C. Crans, A. Tracey (Eds.), Vanadium Compounds: Chemistry Biochemistry and Therapeutic Applications, ACS Symposium Series 711, 1998 (Chapter 12);

(c) A. Butler, Coord. Chem. Rev. 187 (1999) 17.
[5] (a) R.R. Eady, Chem. Rev. 96 (1996) 3013, and references cited therein; (b) C. Rüttiman-Johnson, R. Chatterjee, V.K. Shah, P.W. Ludden, in: D.C. Crans, A. Tracey (Eds.), Vanadium Compounds: Chemistry Biochemistry and Therapeutic Applications, ACS Symposium Series 711, 1998 (Ch. 1).

[6] K.H. Thompson, J.H. McNeill, C. Orvig, Chem. Rev. 99 (1999) 2561.

[7] J. Littlechild, E. Garcia-Rodriguez, E. Coupe, A. Watts, M. Isupov, in: K. Kustin, J. Costa Pessoa, D.C. Crans (Eds.), ACS Series Book 974: Vanadium: The Versatile Metal, 2007, p. 136.

[8] V. Conte, F. Di Furia, G. Licini, Appl. Catal. 157 (1997) 335.

[9] V. Conte, O. Bortolini, Z. Rappoport (Eds.), The Chemistry of Peroxides Transition Metal Peroxides. Synthesis and Role in Oxidation Reactions, Wiley Interscience, 2006, p. 1053, and references cited therein.

[10] O. Bortolini, M. Carraro, V. Conte, S. Moro, J. Inorg. Biochem. 80 (2000) 41.

[11] O. Bortolini, V. Conte, J. Inorg. Biochem. 99 (2005) 1549, and references cited therein.

[12] O. Bortolini, V. Conte, Mass Spectrom. Rev. 25 (2006) 724.

[13] V. Conte, F. Di Furia, S. Moro, in: D.C. Crans, A. Tracey (Eds.), ACS Series Book 711: Vanadium Compounds: Chemistry, Biochemistry and Therapeutic Applications, 1998, p. 136.

[14] O. Bortolini, V. Conte, F. Di Furia, S. Moro, Eur. J. Inorg. Chem. (1998) 1193.

[15] O. Bortolini, M. Carraro, V. Conte, S. Moro, Eur. J. Inorg. Chem. (1999) 1489.

[16] O. Bortolini, M. Carraro, V. Conte, S. Moro, Eur. J. Inorg. Chem. (2003) 42.

[17] P. Wasserscheid, T. Welton, Ionic Liquids in Synthesis, 2nd edition, Wiley-VCH, Weinheim, 2008.

[18] P.T. Anastas, J.C. Warner, Green Chemistry: Theory and Practice, Oxford University Press, New York, 1998.

[19] W. Adam (Ed.), Peroxide Chemistry. Mechanistic and Preparative Aspects of Oxygen Transfer, Wiley-VCH Verlag GmbH, Weinheim, 2000.

[20] J.H. Clark (Ed.), Application of Hydrogen Peroxide and Derivatives, Royal Society of Chemistry, Cambridge, 1999.

[21] V. Conte, F. Di Furia, G. Modena, in: W. Ando (Ed.), Organic Peroxides, John Wiley \& Sons Ltd, 1992, and references cited therein (Chapter 11.2)

[22] A. Butler, M.J. Clague, G.E. Meister, Chem. Rev. 94 (1994) 625, and references cited therein.

[23] V. Conte, B. Floris, Dalton Trans. 40 (2011) 1419.

[24] V. Conte, B. Floris, Inorg. Chim. Acta 363 (2010) 1935.

[25] H. Mimoun, S. Patai (Eds.), The Chemistry of Functional Groups. Peroxides, J Wiley \& Sons Ltd, 1983 (Chapter 15).

[26] G. Strukul, Catalytic Oxidations with Hydrogen Peroxide as Oxidant, Kluwer Academic Publishers, Dordrecht, 1992.

[27] W.A. Herrmann, R.W. Fischer, J.D.G. Correia, J. Mol. Catal. 94 (1994) 213

[28] W. Adam, W. Haas, G. Sieker, J. Am. Chem. Soc. 106 (1984) 5020.

[29] M. Bhattacharjee, S.K. Chettri, M.K. Chaudhuri, N.S. Islam, S.R. Barman, J. Mol. Catal. 78 (1993) 143.

[30] M.N. Bhattacharjee, M.K. Chaudhuri, N.S. Islam, Inorg. Chem. 28 (1989) 2420.

[31] M. Bonchio, O. Bortolini, V. Conte, S. Moro, Eur. J. Inorg. Chem. (2001) 2913.

[32] S. Lovat, M. Mba, H.C.L. Abbenhuis, D. Vogt, C. Zonta, G. Licini, Inorg. Chem. 48 (2009) 4274.

[33] T. Katsuki, K.B. Sharpless, J. Am. Chem. Soc. 102 (1980) 5974.

[34] K.B.Sharpless, Nobel Lecture, http://www.nobel.se/chemistry/laureates/2001/

[35] D.V. Deubel, G. Frenking, P. Gisdakis, W.A. Herrmann, N. Rösch, J. Sundermeyer, Acc. Chem. Res. 37 (2004) 645.

[36] N.K. Kala Raj, A.V. Ramaswamy, P. Manikandan, J. Mol. Catal. 227 (2005) 37.

[37] S. Rayati, M. Koliaei, F. Ashouri, S. Mohebbi, A. Wojtczak, A. Kozakiewicz, Appl Catal. A: Gen. 346 (2008) 65.

[38] (a) P. Adão, J. Costa Pessoa, R.T. Henriques, M.L. Kuznetsov, F. Avecilla, M.R. Maurya, U. Kumar, I. Correia, Inorg. Chem. 48 (2009) 3542; (b) M.L. Kuznetsov, J. Costa Pessoa, Dalton Trans. (2009) 5460

(c) P. Adão, M.R. Maurya, U. Kumar, F. Avecilla, R.T. Henriques, M.L. Kuznetsov, J. Costa Pessoa, I. Correia, Pure Appl. Chem. 81 (2009) 1279.

[39] M.R. Maurya, A. Arya, P. Adão, J. Costa Pessoa, Appl. Catal. A: Gen. 351 (2008) 239.

[40] E. Wojaczyńska, J. Wojaczyński, Chem. Rev. 110 (2010) 4303.

[41] K.P. Bryliakov, E.P. Talsi, Curr. Org. Chem. 12 (2008) 386.

[42] The use of such chiral ligands has been proposed, reviewed by Bolm, see as an example: C. Bolm, Coord. Chem. Rev. 237 (2003) 245.

[43] K.P. Bryliakov, E.P. Talsi, Kinet. Catal. 44 (2003) 334, for an account of those studies.

[44] S.A. Blum, R.G. Bergman, J.A. Ellman, J. Org. Chem. 68 (2003) 150.

[45] D. Balcells, F. Maseras, G. Ujaque, J. Am. Chem. Soc. 127 (2005) 3624.

[46] G.J. Colpas, B.J. Hamstra, J.W. Kampf, V.L. Pecoraro, J. Am. Chem. Soc. 116 (1994) 3627.

[47] C.J. Schneider, J.E. Penner-Hahn, V.L. Pecoraro, J. Am. Chem. Soc. 130 (2008) 2712.

[48] C.J. Schneider, G. Zampella, C. Greco, V.L. Pecoraro, L. De Gioia, Eur. J. Inorg. Chem. (2007) 515.

[49] G. Zampella, P. Fantucci, V.L. Pecoraro, L. De Gioia, J. Am. Chem. Soc. 127 (2005) 953.

[50] G. Zampella, P. Fantucci, V.L. Pecoraro, L. De Gioia, Inorg. Chem. 45 (2006) 7133

[51] G. Zampella, J.Y. Kravitz, C.E. Webster, P. Fantucci, M.B. Hall, H.A. Carlson, V.L. Pecoraro, L. De Gioia, Inorg. Chem. 43 (2004) 4127.

[52] C. Wikete, P. Wu, G. Zampella, L. De Gioia, G. Licini, D. Rehder, Inorg. Chem. 46 (2007) 196.

[53] D. Rehder, G. Santoni, G. Licini, C. Schulzke, B. Meier, Coord. Chem. Rev. 237 (2003) 53. 
[54] M. Mba, M. Pontini, S. Lovat, C. Zonta, G. Bernardinelli, P. Kündig, G. Licini, Inorg. Chem. 47 (2008) 8616.

[55] J. Sun, C. Zhu, Z. Dai, M. Yang, Y. Pan, H. Hu, J. Org. Chem. 69 (2004) 8500.

[56] K.P. Bryliakov, E.P. Talsi, Eur. J. Org. Chem. (2008) 3369.

[57] G. Du, J.H. Espenson, Inorg. Chem. 44 (2005) 5465.

[58] F.P. Ballistreri, G.A. Tomaselli, R.M. Toscano, V. Conte, F. Di Furia, J. Am. Chem. Soc. 113 (1991) 6209.

[59] R. Curci, S. Giannattasio, O. Sciacovelli, L. Troisi, Tetrahedron 40 (1984) 2763.

[60] E. Daire, H. Mimoun, L. Saussine, Nouv. J. Chim. 8 (1984) 271.

[61] M. Bonchio, V. Conte, F. Di Furia, G. Modena, C. Padovani, M. Sivák, Res. Chem. Interm. 12 (1989) 111.

[62] H. Mimoun, L. Saussine, E. Daire, M. Postel, J. Fischer, R. Weiss, J. Am. Chem. Soc. 105 (1983) 3101.

[63] M. Bonchio, V. Conte, F. Di Furia, G. Modena, J. Org. Chem. 54 (1989) 4368.

[64] M. Bonchio, V. Conte, F. Di Furia, G. Modena, S. Moro, J. Org. Chem. 59 (1994) 6262, and references cited therein.

[65] V. Conte, F. Di Furia, G. Modena, J. Org. Chem. 53 (1988) 1665.

[66] F.P. Ballistreri, C.G. Fortuna, A. Pappalardo, G.A. Tomaselli, R.M. Toscano, J. Mol. Catal. A: Chem. 308 (2009) 56.

[67] M. Bonchio, V. Conte, F. Di Furia, G. Modena, S. Moro, J.O. Edwards, Inorg. Chem. 33 (1994) 1631.
[68] J.K. Joseph, S. Singhal, S.L. Jain, R. Sivakumaran, B. Kumar, B. Sain, Catal. Today 141 (2009) 211.

[69] J.E. Remias, T.A. Pavlosky, A. Sen, J. Mol. Catal. A: Chem. 203 (2003) 179.

[70] See as recent example: M.V. Kirillova, M.L. Kuznetsov, V.B. Romakh, L.S Shul'pina, J.J.R. Fraústo da Silva, A.J.L. Pombeiro, G.B. Shul'pin, J. Catal. 267 (2009) 140, and references cited therein.

[71] M.L Kuznetsov, A.J. Pombeiro, Inorg. Chem. 48 (2009) 307, and references cited therein.

[72] Y.N Kozlov, V.B. Romakh, A. Kitaygorodskiy, P. Buglyó, G. Süss-Fink, G.B. Shul'pin, J. Phys. Chem. A 111 (2007) 7736, and references cited therein.

[73] M Bonchio, O. Bortolini, M. Carraro, V. Conte, S. Primon, J. Inorg. Biochem. 80 (2000) 191.

[74] M. Bonchio, O. Bortolini, V. Conte, S. Primon, J. Chem. Soc. Perkin Trans. 2 (2001) 763.

[75] M.J. Clague, N.L. Keder, A. Butler, Inorg. Chem. 32 (1993) 4754

[76] O. Bortolini, C. Chiappe, V. Conte, M. Carraro, Eur. J. Org. Chem. (1999) 3237.

[77] V. Conte, B. Floris, P. Galloni, A. Silvagni, Pure Appl. Chem. 77 (2005) 1575.

[78] (a) A. Silvagni, Ph.D. Thesis, University of Roma Tor Vergata, 2007; (b) V. Conte, B. Floris, P. Galloni, A. Silvagni, Adv. Synth. Catal. 347 (2005) 1341. [79] M. Greb, J. Hartung, F. Köhler, K. Špehar, R. Kluge, R. Csuk, Eur. J. Org. Chem. (2004) 3799. 